\title{
How the absolute growth rate of poplar adapts to the light- $\mathrm{NO}_{3}^{-}$-dosage
}

\author{
G.A. Pieters \\ Department of Plant Physiological Research. Agricultural University. Gen. Foulkesweg 72. 6703 \\ $B W$ Wageningen, The Netherlands
}

\section{Introduction}

The growth of leaves and internodes on a branch of poplar, grown under constant conditions, proceeds according to growth patterns, which: 1) can be defined as organ-specific relations between the relative growth rate (RGR) and the age of the organ; and 2) are independent of irradiance. Consequently, the absolute growth rate of such a branch cannot adapt to irradiance via these growth patterns. A poplar plant adapts its absolute growth rate to high irradiance by a gradually faster production of proportionally larger primordia at its apex. At the same time, the apical volume and the phyllotactic order are increasing. It could be shown that the apical volume is proportional to the rate of leaf area production (Pieters and van den Noort, 1988). Under optimal conditions, the stem elongation rate increases proportionally to the leaf production rate and, on the average, this results in internodes with constant mature length.

Larson (1975) analyzed the development of the vascular system of poplar. The number and the length of the vascular bundles in the vascular cylinder increase in a systematic way; at the same time, phyllotactic order increases. According to Larson's analyses, new procambial traces develop long before the primordia they will serve are visible at the apex.

Combining Larson's data with ours, we established a striking correspondence between the development of the vascular system of poplar, the growth of the organs and the development of absolute growth rate of the plant. Adaptation proceeds via enlargement of the primary vascular system (Pieters and van den Noort, 1988). A larger vascular system is reflected in a larger apical volume and produces proportionally more and larger leaf primordia, which grow out to a proportionally larger final size. Whenever an equilibrium is reached between assimilate production and use in the plant, the primary vascular system stops expansion and the branch grows linearly with time. Because the vascular system develops before the primordia, we suggest that the growth of a plant is a reflection of the development of the vascular system.

Preliminary experiments with sunflower and poplar (Pieters and van den Noort, 
Table I. Scheme of nitrate addition.

\begin{tabular}{|c|c|c|c|c|}
\hline \multicolumn{2}{|c|}{ Irradiance } & \multicolumn{3}{|c|}{ 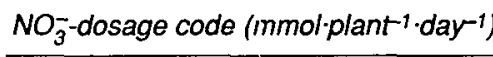 } \\
\hline$W \cdot m^{-2}$ & $\mu m o l \cdot m^{-2} \cdot s^{-1}$ & 1 & 2 & 3 \\
\hline $\begin{array}{r}7.5 \\
30.0\end{array}$ & $\begin{array}{r}32.5 \\
130.0\end{array}$ & $\begin{array}{l}1.0 \\
4.0\end{array}$ & $\begin{array}{l}0.25 \\
1.0\end{array}$ & $\begin{array}{l}0.0 \\
0.0\end{array}$ \\
\hline
\end{tabular}

1985) suggested that the absolute growth rate of a branch adapts in a way similar to that of nitrate dosage. As the availability of (reduced) nitrate in the plant becomes limiting, the expansion of the vascular system stops and the branch grows linearly with time.

The aim of this article is to report the effects of photon fluence rate (PFR) and nitrate dosage on growth and some chemical properties of a poplar branch during the adaptation to a nitrate dosage that is: 1) linear with time, and 2) in proportion to irradiance (cf. Ingestad, 1987).

\section{Materials and Methods}

Fresh cuttings of Populus euramericana (Dode) Guinier cv Robusta, on which one branch was allowed to grow, were cultivated in growth rooms at $22 \%, 60 \% \mathrm{RH}$ and a day length of $16 \mathrm{~h}$ on a nitrate-free culture solution. Nitrate was added daily as a solution of $\mathrm{KNO}_{3}, \mathrm{Ca}\left(\mathrm{NO}_{3}\right)_{2}$ and $\mathrm{Mg}\left(\mathrm{NO}_{3}\right)_{2}$ (molar ratio:
$35: 45: 20$ ), according to the scheme presented in Table I.

Six and four plants were used, respectively, for the 2 highest and the lowest nitrate dosage. Three times per week, length and thickness, respectively diameters of leaves and internodes were measured. The other measurements were made on harvested plants. The plants were harvested 3 times, and those grown at $0.0 \mathrm{mmol} \mathrm{NO}_{3}^{-}$twice.

Chlorophyll was determined according to Bruinsma (196:3), the chemical analyses using the methods described by the Department of Soil Science and Plant Nutrition, AU, Wageningen.

\section{Results}

Relative growth rate $(R G R)$ at half mature length of an organ $\left(R G R_{50}\right)$ was nearly independent of the absolute $\mathrm{NO}_{\overline{3}}$ dosage or PFR (Table II, $\mathrm{NO}_{3}$-codes 1 and 2). At a nitrate dosage of $0.0 \mathrm{mmol} \cdot \mathrm{plant}^{-1} \cdot \mathrm{d}^{-1}$ ( $\mathrm{NO}_{\overline{3}}$ code 3 ) the nitrate reserve in the cutting was rapidly used up and redistribution

Table II. Relative growth rates at half mature length $\left(R G R_{50}\right)$ of leaves and internodes in $\%$ per day.

\begin{tabular}{lllll}
\hline & Leaves & \multicolumn{3}{c}{ Internodes } \\
\hline $\begin{array}{l}\text { Irradiance } \\
\left(\mu \mathrm{mol} \cdot \mathrm{m}^{-2} \cdot \mathrm{s}^{-1}\right)\end{array}$ & 32.5 & 130.0 & 32.5 & 130.0 \\
$R G R_{50}$ & & & & \\
Code of $P F R /$ & & & & \\
nitrate dosage ratio & & 15.5 & 22.4 & 22.8 \\
1 & 14.9 & 15.9 & 22.1 & 21.9 \\
2 & 14.9 & 12.9 & 16.5 & 18.0 \\
3 & 13.1 & & \\
\hline
\end{tabular}


of nitrate could not sustain a high $R G R_{50}$ in growing leaves.

Dry matter- (Fig. 1) and N- (Fig. 2) distribution depended mainly upon the ratio between $P F R$ and nitrate-dosage $(P / N-$ quotient). Also the root-shoot ratio depended on the $P / N$-quotient and not on the absolute PFR or nitrate dosage (see
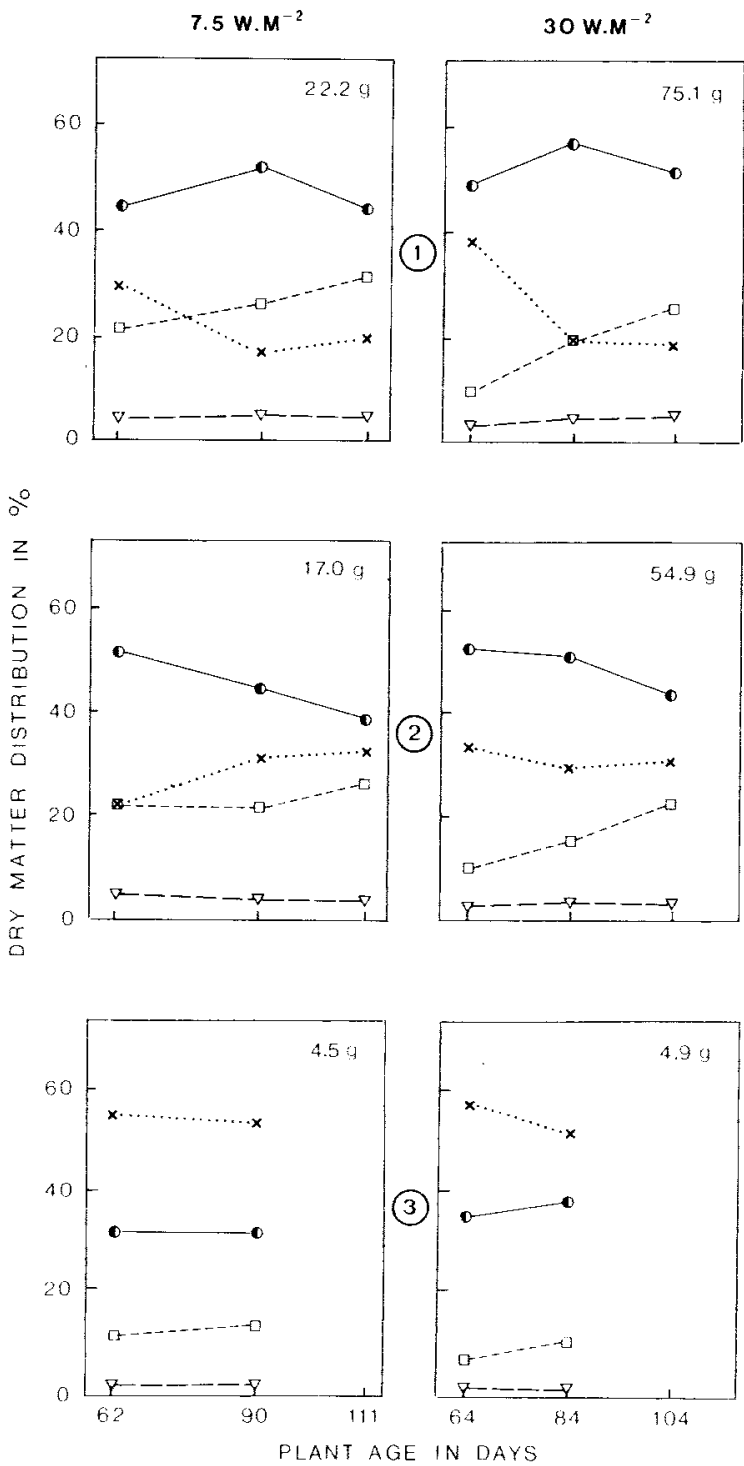

Fig. 1. Mean dry matter distribution over plant parts in \% and absolute mean dry weight per plant versus plant age. Legends for all figures: $\mathbf{O}$ : all leaves; $O$; mature leaves; 0 : growing leaves; $\vee$ : petioles; $\square$ : stem; $x$ : roots. $\mathrm{NO}_{3^{-}}^{-}$ code encircled. 
Fig. 1). At high irradiance, the nitrate concentration (Fig. 2) showed a prolonged adaptation in respect to that of the plants, grown at low irradiance, because the plants continued to grow, while at low irradiance and limiting $\mathrm{N}$-dosage the $\mathrm{N}$-distribution was frozen by induced dormancy (no growing leaves at the last harvest). At
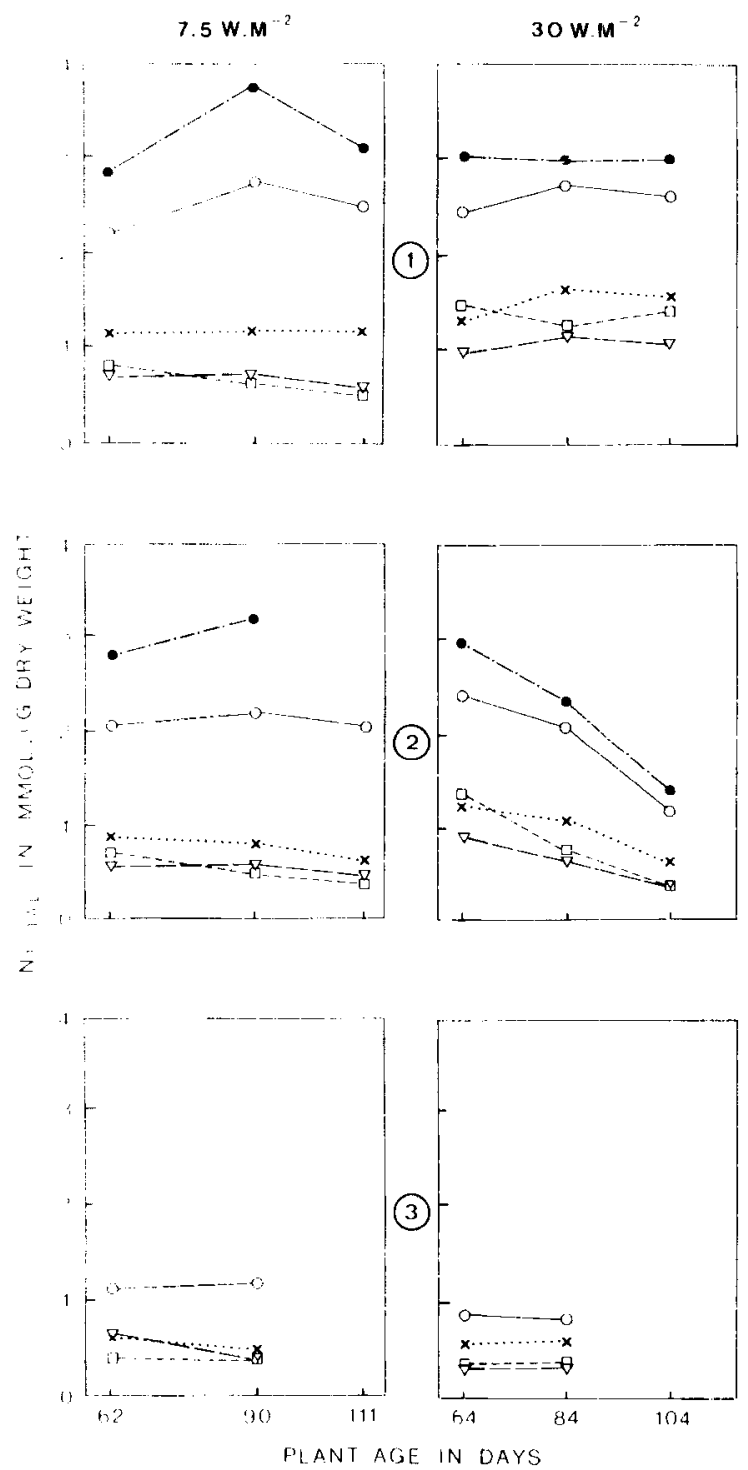

Fig. 2. Distribution of $\mathrm{N}$-total over plant parts versus plant age. For symbols see legend to Fig. 1 . 


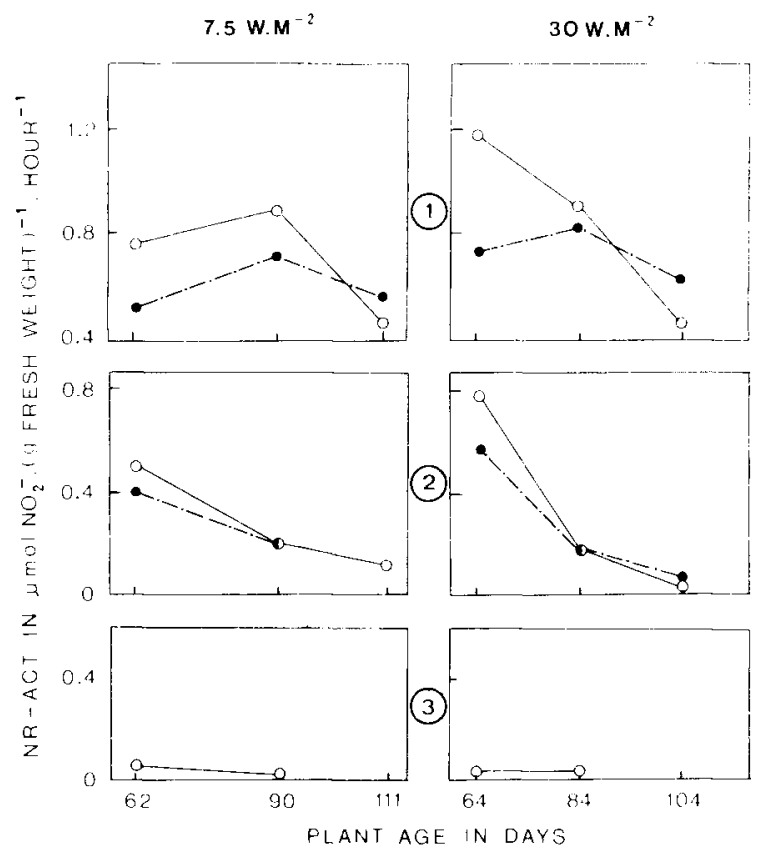

Fig. 3. Nitrate reductase activity of leaf material versus plant age. For symbols see legend to Fig. 1 .

the nitrate dosage of $0.0 \mathrm{mmol}$. plant ${ }^{-1} \cdot$ day $^{-1}$, plants grown at $7.5 \mathrm{~W} \cdot \mathrm{m}^{-2}$ were dormant at the first harvest and those grown at $30 \mathrm{~W} \cdot \mathrm{m}^{-2}$, were dormant at the second harvest. The nitrate deficiency was evenly distributed over mature and growing leaves.

Nitrate-reductase activity (NR-act, Fig. 3) and leaf chlorophyll content (Fig. 4) depended also mainly upon the $P / N$-quotient. As expected, NR-act declined with the (relative) availability of nitrate and with (mean) age of the (increasing) group of older mature leaves. The NR-act of growing leaves was generally lower than that of young mature leaves; this difference became smaller with rising deficiency. NRact in the roots was found to be insignificant.
As expected, chlorophyll content declined with rising deficiency. At high irradiance, thicker leaves were formed: the measured leaf thickness was $220 \mu \mathrm{m}$ in sun leaves and $120 \mu \mathrm{m}$ in shade leaves. The higher chlorophyll contents in leaves of the $30 \mathrm{~W} \cdot \mathrm{m}^{-2}$ plants in respect to $7.5 \mathrm{~W} \cdot \mathrm{m}^{-2}$ plants (Fig. 4) was likely caused by this difference in thickness.

\section{Discussion}

The growth patterns of leaves and internodes are not influenced by the absolute nitrate dosage and irradiance, as judged by the development of individual leaves and internodes in the linear phase of 


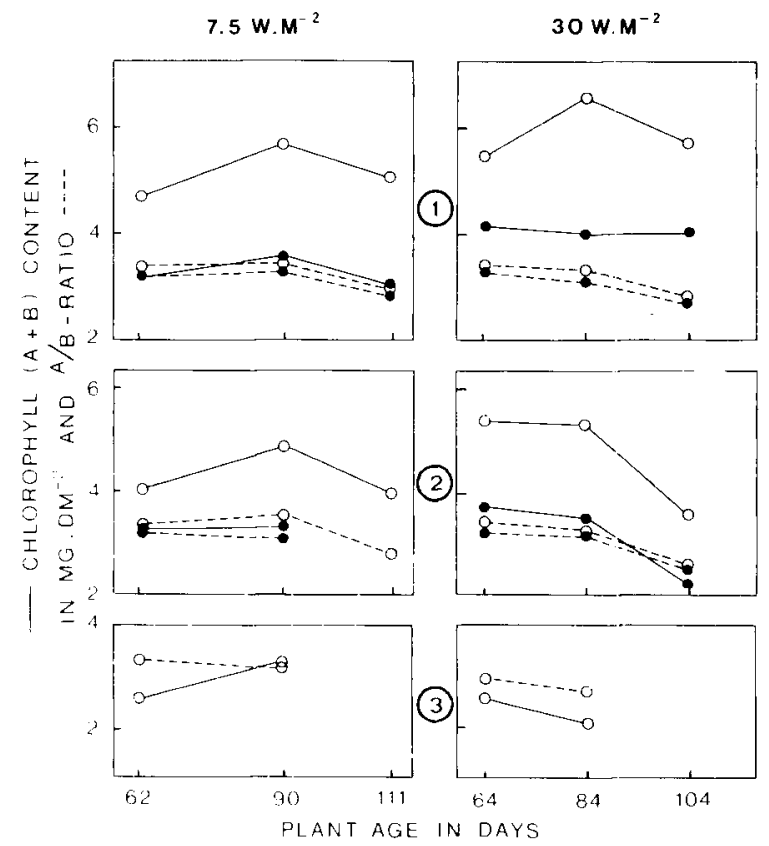

Fig. 4. Chlorophyll ( $A$ and $B$ ) content and $A B$-ratio versus plant age. For symbols see legend to Fig. 1.

growth and by the constancy of relative growth rate at half mature length $\left(R G R_{50}\right)$. The data presented in this paper, therefore, suggest that a plant adapts its absolute growth rate to a linear nitrate dosage, as to $P F R$, through adaptation of the size of the apex, casu quo of the vascular system. The increase in size of the apex of plants, growing in optimal root environment, proceeds linearly with time with a rate proportional to irradiance (data not shown). As explained in the Introduction, a larger apex produces proportionally faster and larger primordia, which grow to maturity according to a pattern independent of PFR and nitrate dosage.

Presumably, plant growth reacts similarly on a deficiency of $\mathrm{PO}_{4}^{3-}$ (members of the Department of Plant Nutrition, AU, personal communication). The plant is not able to adapt to a deficiency of, e.g., $\mathrm{K}^{+}$or
$\mathrm{Mg}^{2+}$ and reacts with immediate deficiency symptoms (Dorenstouter et al., 1985).

Linear dosage of nitrate in proportion to PFR revealed that for optimal growth with minimal deficiency symptoms, an optimal ratio exists between $P F R$ and the dosage of $\mathrm{NO}_{3}^{-}$and, presumably $\mathrm{PO}_{4}^{3-}$. Although we have not yet analyzed this ratio quantitatively, we propose that the constancy of this ratio points to a morphogenetic significance of protein synthesis for the enlargement of the vascular system.

\section{Acknowledgments}

The members of the Department of Soil Science and Plant Nutrition, $\mathrm{AU}$, Wageningen, are duly acknowledged for their help and advice. 


\section{References}

Bruinsma J. (1963) The quantitative analysis of chlorophylls $a$ and $b$ in plant extracts. Photochem. Phytobiol. 2, 241-249

Dorenstouter H., Pieters G.A. \& Findenegg G.R. (1985) Distribution of magnesium between chlorophyll and other photosynthetic functions in magnesium deficient 'sun-' and 'shade-' leaves of poplar. J. Plant Nutr. 8, 1089-1101

Ingestad T. (1987) New concepts on soil fertility and plant nutrition as illustrated by research on forest trees and stands. Geoderma 40, 237252

Larson P.R. (1975) Development and organization of the primary vascular system in Populus deltoides according to phyllotaxy. Am. J. Bot. 62, 1084-1099

Pieters G.A. \& van den Noort M.E. (1985) Leaf area coefficient of some Populus euramericana strains. Photosynthetica 19, 189-193

Pieters G.A. \& van den Noort M.E. (1988) Effect of irradiance and plant age on the dimensions of the growing shoot of poplar. Physiol. Plant. $74,467-472$ 